\title{
Shop until you drop: alternative interpretations
}

\author{
A. P. M. Gorgels (D) A. A. Wilde
}

Accepted: 28 January 2021 / Published online: 22 February 2021

(c) The Author(s) 2021

Dear editor,

Baris and van den Bos should be commended for describing an interesting arrhythmia [1]. However, we would like to offer alternative explanations.

Their ladder diagram comprises sinus rhythm with 2:1 atrioventricular block and a junctional escape rhythm. Our interpretation is as follows:

Group beating is present; QRS complexes after the longer pause are closely followed by a negative $\mathrm{P}$ wave in leads II and III (compare end of QRS complexes with those during sinus rhythm). Clear negative $\mathrm{P}$ waves are seen after the QRS complexes with the shorter R-R intervals. Therefore no sinus rhythm is present, but a junctional escape rhythm (escape interval $1120 \mathrm{~ms}$ ) with shortly coupled retrograde conduction to the atria. Antegrade conduction to the ventricles leads to a reciprocal beat with a long coupling interval $(900 \mathrm{~ms})$. The latter beat also shows retrograde conduction with a longer R-P interval, due to the shorter preceding R-R interval, but without antegrade conduction. This leads to the next junctional escape beat $(1120 \mathrm{~ms})$, followed by the same sequence of events (Fig. 1).

Another mechanism, but less likely, given the vagal state, could be: sinus arrest with an accelerated junc- tional rhythm with 3:2 Wenckebach exit block and retrograde conduction with longer R-P intervals following shorter preceding R-R intervals (Fig. 2).

Conflict of interest A.P.M. Gorgels and A.A. Wilde declare that they have no competing interests.

Open Access This article is licensed under a Creative Commons Attribution 4.0 International License, which permits use, sharing, adaptation, distribution and reproduction in any medium or format, as long as you give appropriate credit to the original author(s) and the source, provide a link to the Creative Commons licence, and indicate if changes were made. The images or other third party material in this article are included in the article's Creative Commons licence, unless indicated otherwise in a credit line to the material. If material is not included in the article's Creative Commons licence and your intended use is not permitted by statutory regulation or exceeds the permitted use, you will need to obtain permission directly from the copyright holder. To view a copy of this licence, visit http://creativecommons.org/licenses/by/4.0/.

\section{References}

1. Baris L, van den Bos EJ. Shop till you drop. Neth Heart J. 2020;28:670-1.

\author{
A. P. M. Gorgels (ه) \\ Department of Cardiology, Maastricht University Medical \\ Centre+, Cardiology Centres of the Netherlands, location \\ Utrecht, Utrecht, The Netherlands \\ tongorgels@gmail.com
}

\section{A. A. Wilde}

Department of Cardiology, Amsterdam UMC, Amsterdam, The Netherlands 


\section{Letter to the Editor}

Fig. 1 One group of repeating changes in QRS intervals and ladder diagram. See text

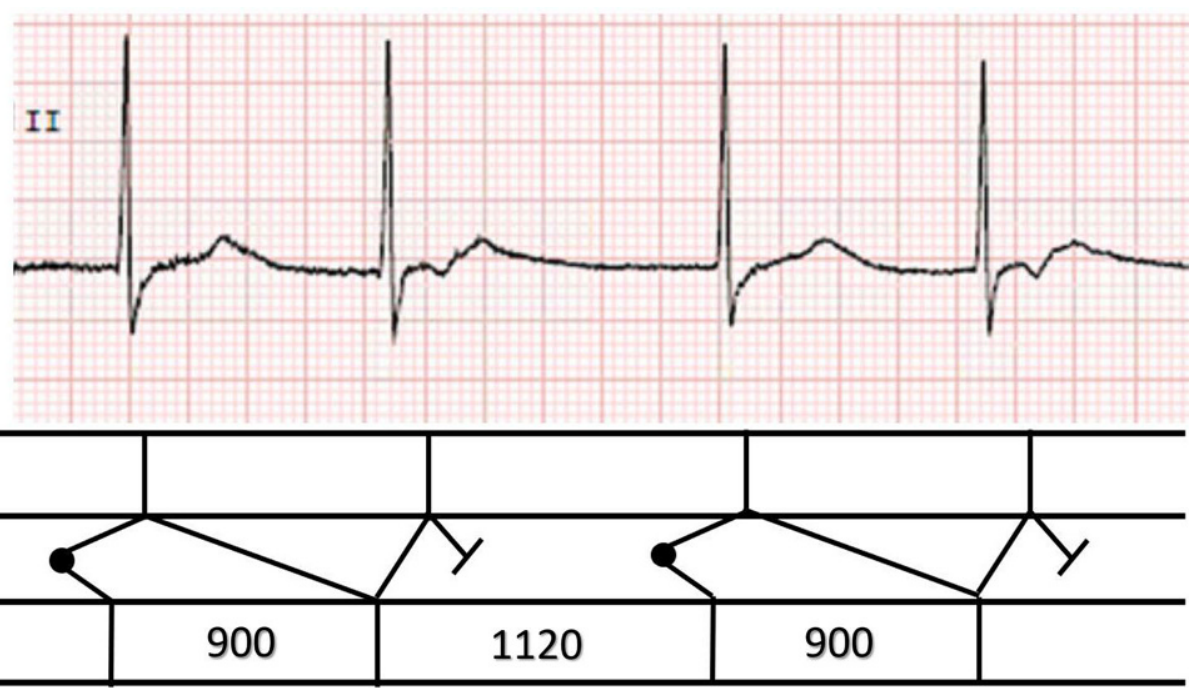

Fig. 2 One group of repeating changes in QRS intervals and ladder diagram. See text
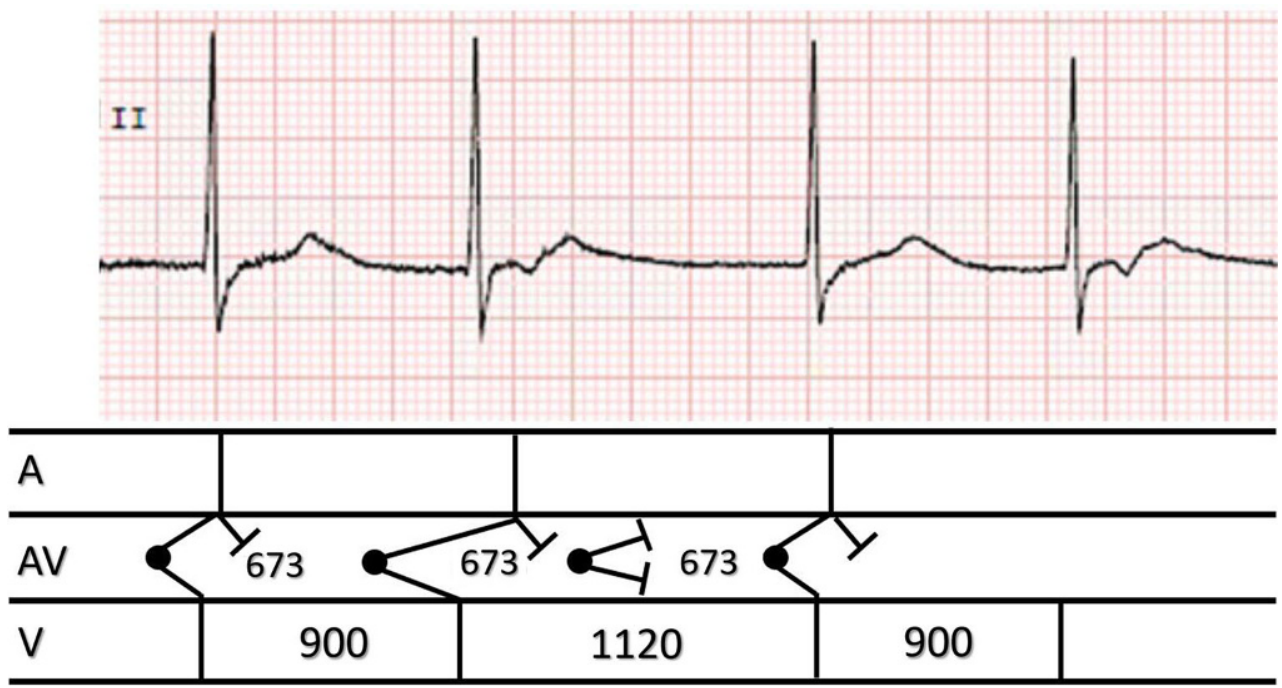